\title{
Growth Parameters for Films of Hydrothermally Synthesized One-Dimensional Nanocrystals of Zinc Oxide
}

\author{
Mohammad A. Mahmood, ${ }^{1}$ Sadaqat Jan, ${ }^{2}$ Ibrar A. Shah, ${ }^{2}$ and Imran Khan \\ ${ }^{1}$ Department of Basic Sciences and Islamiat, University of Engineering and Technology Peshawar, Mardan Campus, \\ Mardan 23200, Pakistan \\ ${ }^{2}$ Department of Computer Software Engineering, University of Engineering and Technology Peshawar, Mardan Campus, \\ Mardan 23200, Pakistan \\ ${ }^{3}$ Department of Telecommunication Engineering, University of Engineering and Technology Peshawar, Mardan Campus, \\ Mardan 23200, Pakistan
}

Correspondence should be addressed to Mohammad A. Mahmood; abbas@uetpeshawar.edu.pk

Received 25 January 2016; Revised 19 March 2016; Accepted 21 March 2016

Academic Editor: Tian-Yi Ma

Copyright (C) 2016 Mohammad A. Mahmood et al. This is an open access article distributed under the Creative Commons Attribution License, which permits unrestricted use, distribution, and reproduction in any medium, provided the original work is properly cited.

\begin{abstract}
Zinc oxide has been the focus of material research due to its potential applications in a variety of novel fields. The material exhibits anisotropic growth in the form of single crystal rods/wires of length in microns and thickness in several tens of nanometers through a facile and low temperature hydrothermal route wherein size, morphology, orientation, and growth rate are strongly dependent on a number of synthesis parameters. In this review article we intend to present/discuss the effects of important growth parameters of zinc oxide that have been reported in the literature. These parameters include concentration of the precursor solution, growth time, role of hexamine, synthesis temperature, $\mathrm{pH}$ of the precursor, and seeding layer deposited on a substrate.
\end{abstract}

\section{Introduction}

1.1. One-Dimensional Zinc Oxide Nanostructures. Zinc oxide $(\mathrm{ZnO})$ has gained substantial importance in the last more than one decade due to phenomenal potential applications of material and its composites in a variety of fields, like photocatalysis/photoelectrocatalysis, biosensors, gas sensors, piezoelectricity, spintronics, optoelectronics, and so forth [112]. Depending upon its synthesis conditions, $\mathrm{ZnO}$ crystals have been found to grow into nanostructures of variety of morphologies. These include nanorods, nanotubes, nanobelts, nanohelixes, nanosprings, nanorings, nanocombs, nanocages, nanoneedles, and nanoflower [13-18]. Being a semiconductor with a suitably wide band gap $(3.37 \mathrm{eV})$, having high exciton binding energy $(60 \mathrm{meV})$, and being able to be grown in a desired shape, the material has aroused the interest of material researchers and engineers for its utilization in device fabrication through the bottom up approach.
Having lattice parameters $a=0.3296 \mathrm{~nm}$ and $c=$ $0.526065 \mathrm{~nm}$, a $\mathrm{ZnO}$ crystal normally grows into wurtzite hexagonal structure wherein $\mathrm{O}^{2-}$ and $\mathrm{Zn}^{2+}$ ions form alternate planes. Each $\mathrm{O}^{2-}$ and $\mathrm{Zn}^{2+}$ ion in their corresponding planes is tetrahedrally linked with their four neighbors (Figure 1). With this arrangement of ions the crystal loses symmetry about its central axis; as a result the material exhibits piezoelectric properties. Furthermore, the positive charge on zinc ions and negative charge on oxygen ions give rise to a net positive and negative charge on the basal planes $(0001)$ and $(000 \overline{1})$, respectively. This makes the crystal polar with its polarization vector along the $c$-axis [19]. Naturally, a surface with net electric charge is highly unstable. However, the basal faces of $\mathrm{ZnO}$ crystal are stable and do not show any surface reconstruction due to which they remain flat $[20,21]$. Reasons of the stability of the polar surfaces of $\mathrm{ZnO}$ crystal are unknown yet; however, intensive research efforts are underway in this connection [22-25]. Apart from the polar basal planes, two commonly observed facets in 


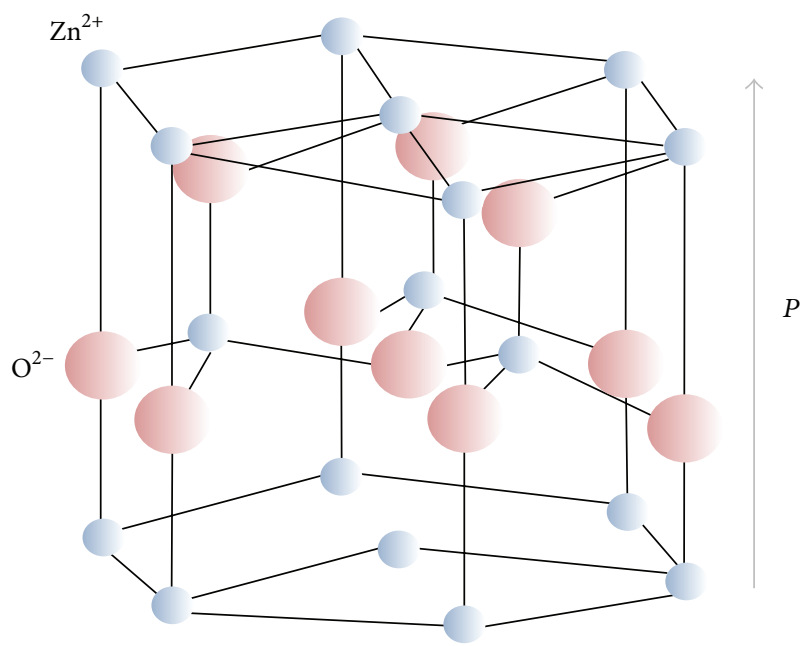

FIgURE 1: Hexagonal structure of wurtzite zinc oxide.

the wurtzite hexagonal $\mathrm{ZnO}$ crystal are $\{2 \overline{1} \overline{1} 0\}$ and $\{01 \overline{1} 0\}$ which are stable for being nonpolar and have therefore low surface energies $[19,26]$.

The formation of different shapes during the synthesis of $\mathrm{ZnO}$ arises from the anisotropic growth of the crystal during which the ions in the precursor attach preferentially to polar crystal face with respect to the other. This preferential attachment depends upon the surface energy and number of active sites present per unit area of the face. As a rule of thumb, a face with high surface energy is more unstable and has a natural tendency of minimizing this energy by attracting and adsorbing more particles from the precursor. Consequently, the crystal grows in the direction normal to the high energy face while faces with lower energy expand. Generally, $\mathrm{ZnO}$ crystals exhibit faster growth along certain directions, that is, $\pm[2 \overline{1} \overline{1} 0], \pm[01 \overline{1} 0]$, and $\pm[0001]$. Together with the polar faces, growth rates of $\mathrm{ZnO}$ crystals could be tuned along any of these directions rendering the material to assume novel nanostructures [19].

Synthesis of $\mathrm{ZnO}$ nanostructures could be done either through solution phase or gaseous phase route $[8,13]$. Synthesis through solution phase includes sol-gel technique using nanocolloid of hydrated zinc acetate [27], alcoholic solutions of hydrated zinc acetate along with $\mathrm{NaOH}$ or tetramethylammonium hydroxide (TMAH) [28-30], growth with the help of template [31], electrophoresis [32], and spray pyrolysis $[33,34]$. The gaseous phase synthesis, on the other hand, includes techniques like physical vapour deposition (PVD) [35], chemical vapour deposition (CVD) [36], metal organic chemical vapour deposition (MOCVD) [37], vapour-solid (VS) and vapour-liquid-solid (VLS) [3841], thermal oxidation [42], and thermal decomposition through microwave irradiation [43].

1.2. Hydrothermal Synthesis of ZnO Nanorods. One-dimensional (1D) $\mathrm{ZnO}$ nanostructures (nanorods and nanowires) have gotten popular for variety of high technology applications, like optoelectronic device, gas sensors, solar cells, and photocatalysts. Controlled synthesis in the form of arrays attached to some solid substrate and high efficiency stemming from the large specific surface area are the major benefitting aspects of the one-dimensional nanostructures. The low temperature hydrothermal synthesis route for the one-dimensional $\mathrm{ZnO}$ nanostructures is the one which is characterized by its low cost, simplicity, and minimum environmental impacts. The hydrothermal synthesis of $\mathrm{ZnO}$ nanorods was pioneered by Vergés et al. (1990) [44]; nevertheless, the controlled synthesis of $\mathrm{ZnO}$ nanorod arrays on a solid substrate was brought forward by Vayssieres et al. (2001) [45]. The report aroused interest among the researchers for the applications of the as-synthesized $\mathrm{ZnO}$ nanorod arrays. The fabrication technique, presented in the report, involves dipping of the substrate into the aqueous precursor solution of zinc nitrate and hexamethylenetetramine (HMT), commonly known as hexamine or methenamine, at specific temperature. As a presynthesis step, a clean substrate was seeded with presynthesized $\mathrm{ZnO}$ nanoparticles. These seeds act as nucleation centers over which the oxygen anions $\left(\mathrm{O}^{2-}\right)$ and zinc cations $\left(\mathrm{Zn}^{2+}\right)$ settle down and form alternate planes of oxygen and zinc stacked together to form hexagonal rods oriented, exclusively, along $c$-axis. The perceived growth mechanism involves thermal decomposition of hexamine to produce hydroxyl ions which react with $\mathrm{Zn}^{2+}$ ions forming $\mathrm{ZnO}$ as an ultimate product. The whole process has been summarized in the following chemical equations [46]:

$$
\begin{aligned}
\left(\mathrm{CH}_{2}\right)_{6} \mathrm{~N}_{4}+6 \mathrm{H}_{2} \mathrm{O} & \longleftrightarrow 6 \mathrm{HCHO}+4 \mathrm{NH}_{3} \\
\mathrm{NH}_{3}+\mathrm{H}_{2} \mathrm{O} & \longleftrightarrow \mathrm{NH}_{4}^{+}+\mathrm{OH}^{-} \\
2 \mathrm{OH}^{-}+\mathrm{Zn}^{2+} & \longleftrightarrow \mathrm{ZnO}(\mathrm{s})+\mathrm{H}_{2} \mathrm{O}
\end{aligned}
$$

\section{Zinc Oxide Growth Parameters}

There are several parameters which have significant effects on the morphology, aspect ratio, and the overall efficiency of the as-synthesized $\mathrm{ZnO}$ nanorods. Nevertheless, optimization of these parameters depends upon the specific application in which the as-fabricated samples are used. However, a general discussion on the effects of these parameters on the morphology and efficiency is going to be presented. Some of the major parameters involved in the hydrothermal synthesis include precursor concentration, precursor $\mathrm{pH}$, growth time, growth temperature, hexamine, seeding, and annealing.

2.1. Precursor Concentration. Precursor solution used in the hydrothermal growth acts as a source of $\mathrm{Zn}^{2+}$ ions for the formation of $\mathrm{ZnO}$ nanostructures. Obviously, the growth rate would vary with the precursor concentration. Gou et al. (2005) [47], while investigating the effect of precursor concentration on the morphology of $\mathrm{ZnO}$ nanorods synthesized on a premodified substrate, have observed that the precursor concentration has a significant effect on the diameter of the hexagonal nanorod. The average rod diameter was noticed to decrease with decreasing the concentration. The relationship was, however, not linear. In a high concentration regime decreasing the precursor concentration to half causes 
a decrease in the average rod diameter to one-third, while in the low concentration range a large change in the concentration causes only a small change in the rod thickness. Another important observation was that the diameter distribution of the rods, in the low concentration regime, is quite narrow compared to that observed for high concentration regime. As per the observation of Le et al. (2006) [48], an increase in the concentration of $\mathrm{Zn}^{2+}$ from $0.01 \mathrm{M}$ to $0.033 \mathrm{M}$ increased the length of the as-synthesized rods from $400 \mathrm{~nm}$ to $1.5 \mu \mathrm{m}$, while average diameter was observed to decrease from 160 to $100 \mathrm{~nm}$. However, Wang et al. (2008) [49] observed a simultaneous increase from 43 to $70 \mathrm{~nm}$ and from 65 to $320 \mathrm{~nm}$ in diameter and length, respectively, when the precursor concentration was increased from 8 to $40 \mathrm{mM}$. Lee et al. (2007) [50] have reported that, with increasing the reactant concentration from 10 to $70 \mathrm{mM}$, the average diameter and length of as-grown rods increased, respectively, from 370 to $930 \mathrm{~nm}$ and 2.1 to $5.5 \mu \mathrm{m}$, causing a slight increase in the aspect ratios from 5.8 to 5.9. Xu et al. (2008) [51] have found a close relationship between the precursor concentration and density of the as-grown nanorod. The relationship has been attributed to the formation of more nucleation sites in a high concentration precursor. The tendency for the formation of additional nucleation sites in higher precursor concentration is thermodynamically favorable. However, at some later stage of the growth process the relationship ceases to continue but rather gets reversed; that is, the density slightly decreases as the concentration increases. This is due to the lateral growth of the rod. From these observations, one can easily see that there is a lack of consistency which is understandable due to the intricate interrelationship among the wide range parameters involved in the synthesis process. However, one observable trend is that growth rate of $\mathrm{ZnO}$ nanorods increases, both laterally and longitudinally, with precursor concentration. In an experimental work published by Mahmood et al. (2013), the authors observed that nanorod films synthesized in $10 \mathrm{mM}$ aqueous solution of zinc contents were relatively more efficient in photocatalysis [52]. The high efficiency was attributed to the high surface area of the assynthesized nanorod film.

2.2. Effect of Growth Time. In principle, the lateral as well as longitudinal growth of $\mathrm{ZnO}$ nanorod should exhibit the same trend in case of elongated synthesis time as has been observed for the variation in the precursor concentration. Pei et al. (2010) [53], while fabricating $\mathrm{ZnO}$ nanorod arrays on zinc substrates at elevated temperature $\left(350^{\circ} \mathrm{C}\right)$ using autoclave, have observed that, by extending the growth time from $1 \mathrm{~h}$ to $20 \mathrm{~h}$, the length of the nanorods concomitantly increased from $2 \mu \mathrm{m}$ to $48 \mu \mathrm{m}$, while the diameter remained almost constant. In the low temperature conditions $\left(\sim 95^{\circ} \mathrm{C}\right)$ Baruah and Dutta (2009) [54] have observed that, in a total of $20 \mathrm{~h}$ period, the growth took place at maximum rate during the first five hours after which it slowed down, gradually. The decrease in the concentration of $\mathrm{Zn}^{2+}$ ions was accounted for. To maintain the high growth rate, it was recommended that the precursor should be periodically replenished after every five hours throughout the process. Xu et al. (2008)
[51] have come up with similar observations and stated that in the initial half hour the growth along the nonpolar direction is faster and the nanorods grow laterally. In the subsequent period, extending from 0.5 to 6 hours the growth predominantly occurs along the polar direction [0001] which results in the elongation of the rods, while from 6 to $48 \mathrm{~h}$ the growth is significant both laterally and longitudinally.

2.3. Role of Hexamine. The role of hexamine in the synthesis process of $\mathrm{ZnO}$ nanorods is still not quite clear. The generally perceived function of hexamine is to provide $\mathrm{OH}^{-}$ions for the formation of $\mathrm{ZnO}$. However, Ashfold et al. (2007) have opined that hexamine serves as kinetic buffer of solution $\mathrm{pH}$ [55]. The report further states that at the start of the synthesis process the number of $\mathrm{Zn}^{2+}$ ions and the $\mathrm{pH}$ level of the precursor are such that the formation of $\mathrm{ZnO}$ occurs through $\mathrm{Zn}(\mathrm{OH})_{2}$. However, with the passage of time the concentration of $\mathrm{Zn}^{2+}$ ions goes down and $\mathrm{pH}$ of the precursor rises. In such conditions the formation of $\mathrm{Zn}(\mathrm{OH})_{2}$ is thermodynamically not favored and the subsequent growth takes place with the direct deposition of $\mathrm{ZnO}$. While commenting on the role of hexamine in the hydrothermal synthesis of $\mathrm{ZnO}$ nanorods, Sugunan et al. (2006) [56] have proposed that hexamine is a nonpolar long chain polymer which preferentially attaches to and covers all the nonpolar faces of the $\mathrm{ZnO}$ crystal as shown in Figure 2. This allows the incoming ions from the precursor to attach at the polar (0001) face for epitaxial growth along $c$-axis. In this sense the role of hexamine is that of a chelating agent and defines shape of the as-grown nanorods.

The optimum molar ratio of the zinc source and hexamine in the precursor for the hydrothermal synthesis of $\mathrm{ZnO}$ nanorods is $1: 1$. Using the ultraviolet protection factor (UPF), Zhou et al. (2010) [57] have shown that the concentration of hexamine relative to that of $\mathrm{Zn}^{2+}$ ions has a profound impact on the crystal quality of the as-synthesized nanorods. The UPF values below 15, in between 15 and 50, and above 50 are, respectively, classified as poor, good, and excellent UV blocking property of the fabrics. The report has demonstrated that $\mathrm{ZnO}$ nanorods grown on PET fabrics exhibited excellent crystal quality for the reactant molar ratio of $1: 1$ because the as-grown rods have the highest UPF values at this ratio. These results are depicted in Figure 3.

2.4. Effect of Synthesis Temperature. Like other parameters, growth temperature also has a profound effect on the morphology of $\mathrm{ZnO}$ nanostructures (nanorods). Xu et al. (2008) [51] have studied the effect of temperature on the hydrothermal growth of $\mathrm{ZnO}$ nanorods and have reported that synthesis temperature has a significant contribution in defining the aspect ratios of the as-synthesized nanorods. The report further stated that $70^{\circ} \mathrm{C}$ has been found as optimum temperature in this regard. By reducing temperature to $60^{\circ} \mathrm{C}$ the aspect ratio was observed to decrease. The aspect ratio arises from the relative growth along the longitudinal and lateral directions. The report suggests that the nanorods growth depends upon the availability of $\mathrm{OH}^{-}$ions in the precursor. These anions are formed due to the thermal decomposition of hexamine. At higher temperature, a large number of 


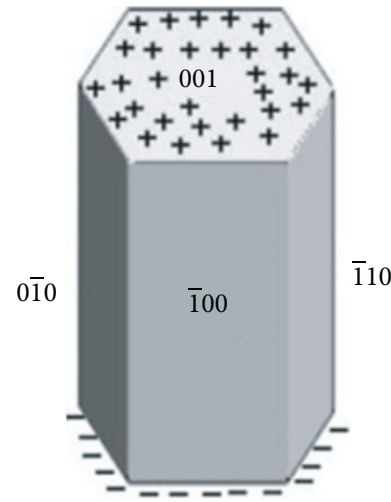

(a)

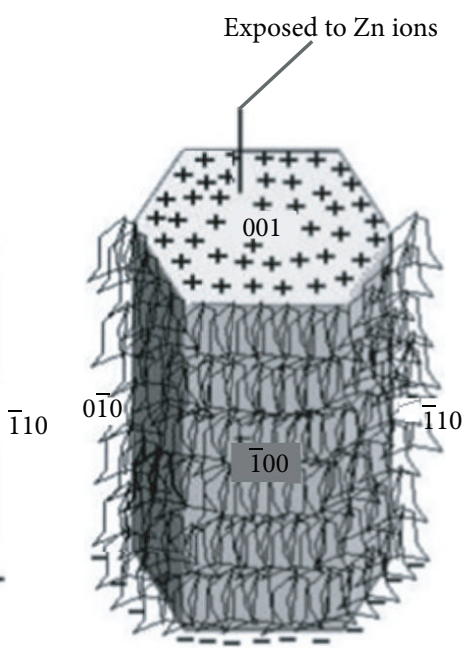

(b)

FIGURE 2: Attachment of hexamine to the nonpolar facets of the zincite crystal allows the growth of the crystal in the (0001) direction. (a) Hexagonal $\mathrm{ZnO}$ crystal and (b) possible attachment of hexamine on to the nonpolar facets leaving the polar face exposed allowing further crystal growth along the $c$-direction (reproduced with the permission from [56]).

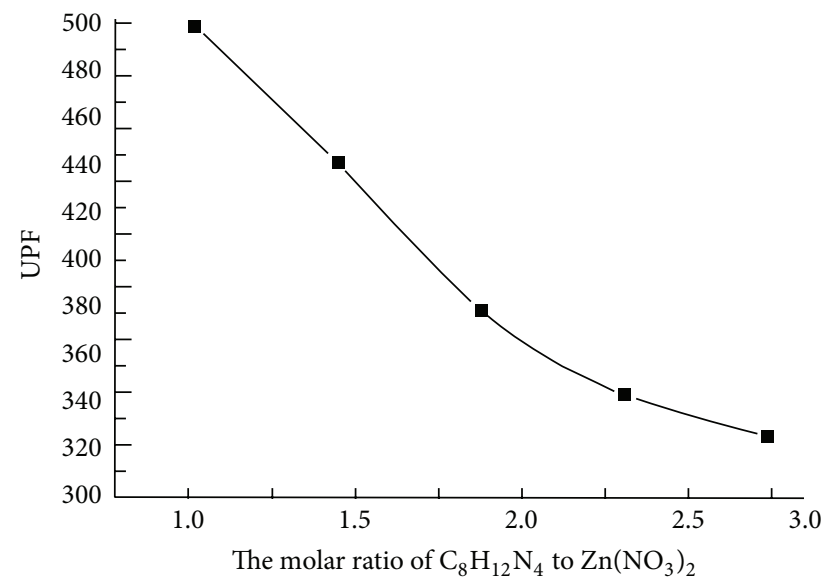

FIgure 3: The effect of molar ratio between $\mathrm{C}_{8} \mathrm{H}_{12} \mathrm{~N}_{4}$ and $\mathrm{Zn}\left(\mathrm{NO}_{3}\right)_{2}$ on UV blocking property of fabric (reproduced with the permission from [57]).

hexamine molecules undergo instant decomposition and create as many $\mathrm{OH}^{-}$ions. This causes faster growth both laterally and longitudinally. But with the passage of time as the concentration of $\mathrm{OH}^{-}$ions goes down the competition for the preferential attachment at the (0001) face decreases and most of the available $\mathrm{ZnO}$ has the chance to settle at the top of growing structure. This results in the growth of a hexagonal pyramid with broad base and pointing top. Contrary to this, the growth at comparatively lower temperature proceeds uniformly as the decomposition of hexamine occurs with a uniform mild rate. In such a case, the competition for the (0001) face remains almost constant and a considerable amount of $\mathrm{ZnO}$ does not have the chance to adsorb at the top and hence attach to the side in such a way that the rods grow with uniform thickness. The two cases can be seen in Figure 4.
The effect of synthesis temperature has also been investigated by Tang et al. (2008) [58] who were synthesizing $\mathrm{ZnO}$ nanorods in a precursor containing zinc acetate and surfactant, like polyvinyl alcohol (PVA), polyethylene glycol (PEG), sodium dodecyl sulfate (SDS), or cetyltrimethylammonium bromide (CTAB), at elevated temperatures of 130, 150 , and $180^{\circ} \mathrm{C}$ for $5 \mathrm{~h}$. The report states that the product synthesized with PVA at $130^{\circ} \mathrm{C}$ is composed of cubes, spheres, and other shapes with wide size distribution. But at $150^{\circ} \mathrm{C}$ the product was composed predominantly of needle-like structures. However, sample synthesized at $180^{\circ} \mathrm{C}$ is composed exclusively of $\mathrm{ZnO}$ nanorods with almost uniform dimension. Variation in the diameter of hydrothermally grown $\mathrm{ZnO}$ nanorods with the synthesis temperature has also been reported by Guo et al. (2005) [59]. Through oxidizing $\mathrm{Zn}$ vapours, Hou et al. (2009) [60] produced morphologies like $\mathrm{ZnO}$ multipods, tetrapods, nanoneedles, and nanowires by adjusting the growth temperatures at 620 , 770,840 , and $900^{\circ} \mathrm{C}$, respectively. Also, Li et al. (2008) [61] have reported that single crystal $\mathrm{ZnO}$ nanostructures with different morphologies as flower-like and cabbage-like were synthesized at different temperatures, that is, 120,150, and $180^{\circ} \mathrm{C}$. Similarly, Wahab et al. (2009) [62] have found that the variation of temperature from 40 to 60 to 80 and to $100^{\circ} \mathrm{C}$ caused the variation in morphology of the as-synthesized products from particle to star-shape to rosette-shape and to individual nanorod shape, respectively, as shown in Figure 5.

2.5. Effect of the Precursor's $p H$. Among the variety of parameters, $\mathrm{pH}$ of the precursor also has a profound effect on the growth rate and morphology of the $\mathrm{ZnO}$ nanostructures fabricated through hydrothermal route. The effect has been studied in detail by Baruah and Dutta (2009) [54]. There is a spontaneous increase in the $\mathrm{pH}$ level of the growth precursor which is attributed to the thermal decomposition of 


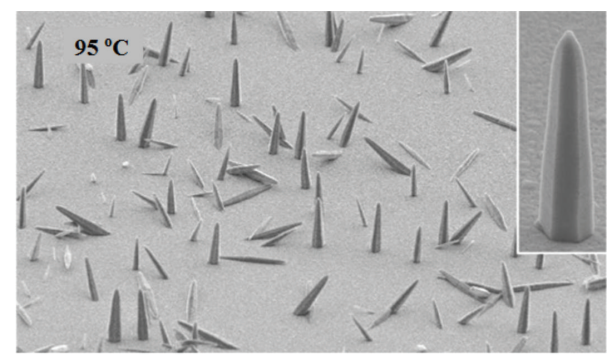

(a)

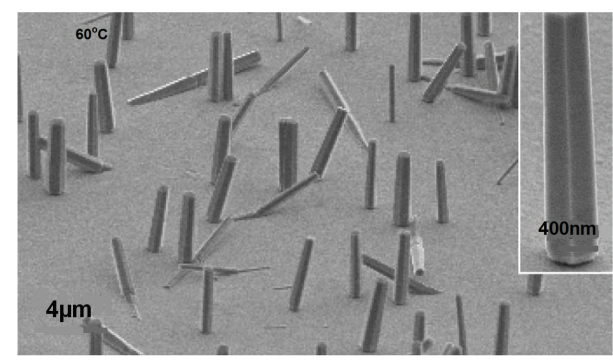

(b)

FIgURE 4: $\mathrm{ZnO}$ nanorods grown at different temperatures [51].

the hexamine and the concomitant generation of $\mathrm{OH}^{-}$ions. The report demonstrates that change of the precursor from acidic to basic occurs at the initial stage depending upon the concentration. Figure 6 shows that solution with high reactant concentration changes within the first hour of the growth process.

The figure further reveals that rods growth occurs faster in the basic medium than in the acidic one. The effect of initial $\mathrm{pH}$ value of the precursor solution on the morphology of the as-synthesized samples can be seen in Figure 7, wherein a gradual increase in the $\mathrm{pH}$ changes the morphology from rod- to flower-like. The highest growth rate was observed at $\mathrm{pH}$ of 7.3, while for $\mathrm{pH}$ above this value the rods start dissolving. Conversion of morphology from particle to hexagonal nanorods, with $\mathrm{pH}$ variation from 3 to 9, was also observed by Sridevi and Rajendran (2009) [63]. Song et al. (2008) [64], while investigating the role of $\mathrm{OH}^{-}$ions in the hydrothermal growth $\mathrm{ZnO}$ nanorods, have found the highest growth rate at $\mathrm{pH}$ 10.6. This was verified through the observation that the dissolution of $\mathrm{ZnO}$ by the $\mathrm{OH}^{-}$ions was minimum at this $\mathrm{pH}$ value. Akhavan et al. (2009) [65] observed that the growth of the rods in his experiment was the fastest at $\mathrm{pH}$ of 11.33, while synthesis at this $\mathrm{pH}$ level caused considerable decrease in the band gap of $\mathrm{ZnO}$ showing that the fast growth caused high concentration of defects in the crystal.

Fabricating $\mathrm{ZnO}$ nanorods over seeded carbon nanotubes (CNTs), Li et al. (2008) [66] have suggested that the low density of $\mathrm{ZnO}$ nanorods grown at $\mathrm{pH}$ of 7 could be attributed to the heterogeneous as well as homogeneous nucleation because of the high concentration of $\mathrm{OH}^{-}$ions. On reaching the $\mathrm{pH}$ of 7.1, large flocs of $\mathrm{Zn}(\mathrm{OH})_{2}$ appeared in the precursor. This inhibited the rods growth over the CNTs through heterogeneous nucleation throughout the solution body. Contrary to this, significantly high density rods were found to grow for $\mathrm{pH}$ variation in the range 6.8-5.0. This might have occurred due to the prevalent thermodynamically preferred heterogeneous nucleation at the seeded $\mathrm{ZnO}$ particles. Further decrease in the $\mathrm{pH}$ level resulted in the formation of thin rods due to the concomitant decrease in the supply of $\mathrm{OH}^{-}$ions.

2.6. Effect of Seeding. The morphologies of the as-synthesized $\mathrm{ZnO}$ nanorods have been observed to be strongly dependent upon parameters, like precursor concentration, precursor
$\mathrm{pH}$, synthesis temperature, growth time $[48,54]$, and so forth. Nevertheless, several other aspects like rod's density, orientation, facial distribution, thickness variation, and attachment to the substrate, which in turn have profound effect on the efficiency of the as-fabricated samples, are dependent exclusively upon the quality of the seeding layer [67]. The nanocrystallite seeds are hypothesized to provide heterogeneous nucleation sites for the crystallization of $\mathrm{ZnO}$ during the growth process of the nanorods. $\mathrm{ZnO}$ is a polar molecule with partial positive charge at zinc end and partial negative charge at the oxygen end. The existence of these electric dipoles over the molecules of $\mathrm{ZnO}$ gives rise to the growth of single crystal $\mathrm{ZnO}$ along the $c$-axis of its wurtzite structure. It has been seen that the (0001) plane of the $\mathrm{ZnO}$ crystal is the preferred site for attachment of molecules in the surrounding that results in the growth of single crystal hexagonal nanorods with the top polar plane and six nonpolar side planes. This indicates that for a seeding layer only those crystallites can grow into the rod morphology which have their (0001) plane exposed to the precursor solution. Obviously, the more number of such crystallites present per unit area of the substrate surface gives rise to the growth of more dense rods. Also, implanting the seeding crystallites with their [0001] orientations aligned with normal to the substrate surface results in the synthesis of well aligned nanorods. This shows that deposition of the seeding layer is critically important for the subsequent synthesis of dense and well aligned nanorod arrays. This can be observed from the SEM images given in Figure 8, taken from the report by Guo et al. (2005) [47] in which $\mathrm{ZnO}$ nanorods were grown on bare and $\mathrm{ZnO}$ seeding film coated surfaces.

There are numerous reports in the literature on the deposition of $\mathrm{ZnO}$ seeding layers on solid substrates and their effects on the efficiencies of the subsequently grown nanorods. The techniques appeared in the literature could be divided into two main categories. One of the two involves the gas-phase deposition methods, while the other is the liquid-phase synthesis techniques. Both types have their respective advantages and disadvantages in terms of their procedures, costs, environmental impacts, and efficiencies in terms of the subsequently fabricated nanorod arrays. Generally, the gas-phase deposition techniques involve harsh conditions, like high temperatures or vacuum, which require high tech sophisticated equipment. These techniques provide 


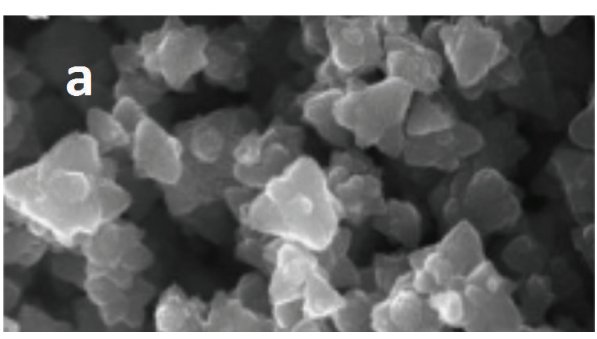

(a)

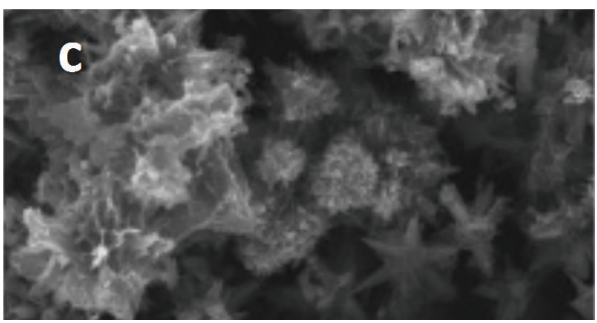

(c)

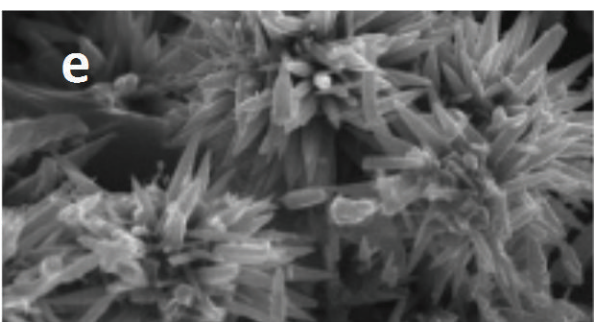

(e)

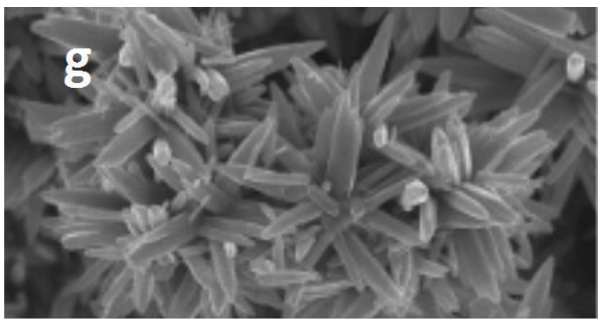

(g)

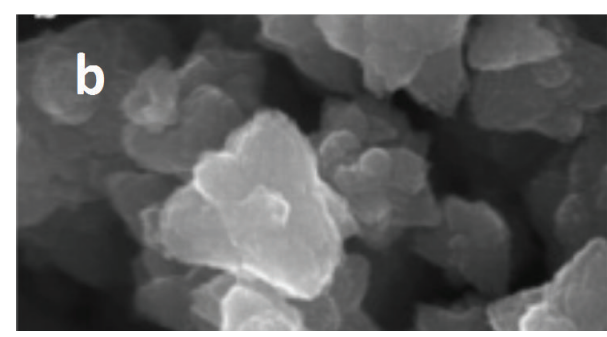

(b)

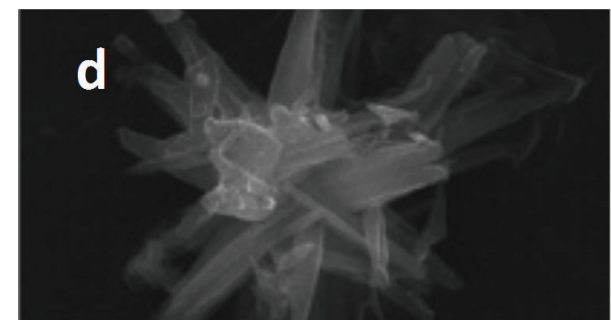

(d)

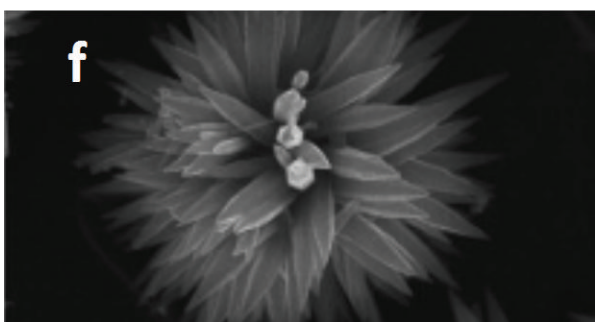

(f)

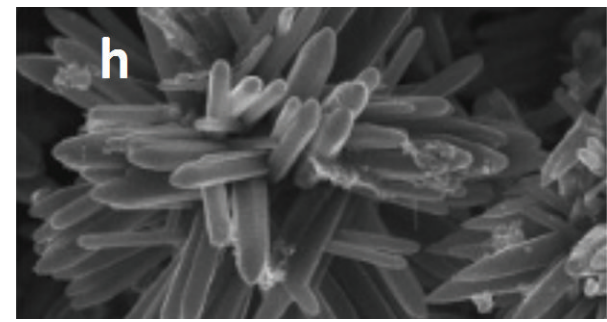

(h)

Figure 5: Low and high resolution FESEM images of (a and b) stirred sample and samples synthesized/refluxed at (c and d) $40^{\circ} \mathrm{C}$, (e and f) $60^{\circ} \mathrm{C},(\mathrm{g})$ at $80^{\circ} \mathrm{C}$, and $(\mathrm{h})$ at $100^{\circ} \mathrm{C}$ for $20 \mathrm{~min}$ each [62].

good control over the fabrication parameters which could lead to the desired result. However, need for costly tools may preclude its large scale applications. The liquid-phase deposition methods, on the other hand, are quite simple and cheap but are time consuming and also provide limited control over the synthesis parameters which affect the quality of the end products. Hence, there is a tradeoff between the two types.

Wang et al. (2009) [68] have studied the relative efficiencies of seed layers deposited on Si substrates using DC reactive sputtering and RF magnetron sputtering techniques. In the XRD patterns of the film it was observed that DC reactive sputtered sample had prominent peak of (103) orientation, while in the RF magnetron sputtered sample had (002) face with the highest intensity. Since the (002) face is the preferred plane for the $\mathrm{ZnO}$ crystal growth, therefore, no rods were observed to grow on the DC reactive sputtered substrate. On the other hand, a copious number of welldefined hexagonal rods were obtained over the RF sputtered sample. Further, among the RF sputtered samples it was seen that the one which was done with the higher power produced highly dense and well aligned rods as compared to the one which was sputtered with lower power. In another report by Tao et al. (2010) [69], three samples of seeding layers were prepared through RF magnetron sputtering. Details of the working parameters for all the three samples are given in Table 1. Comparison of $\mathrm{ZnO}$ nanorod arrays, grown on all the three samples, shows that, by keeping all the other parameters constant in the RF sputtering deposition, it is the amount of oxygen in the working gas mixture which influences the 


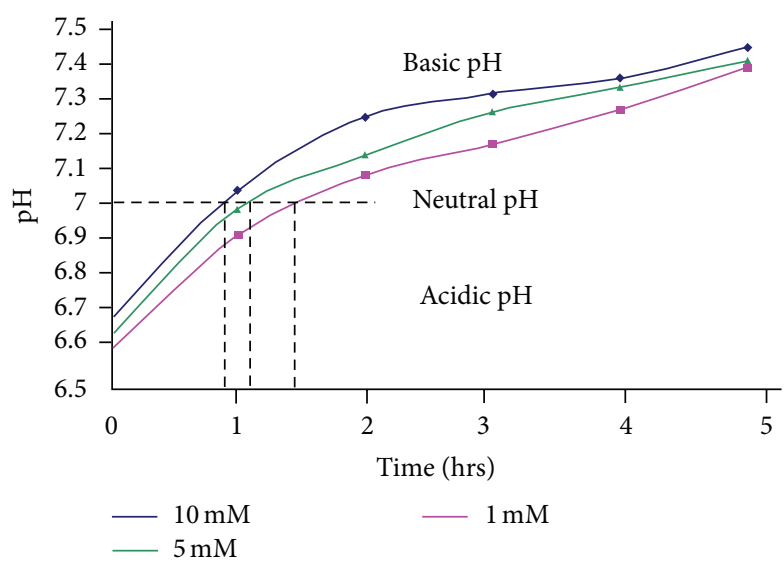

FIgURE 6: Change in $\mathrm{pH}$ of the reaction bath over a period of 5 hours during the growth of $\mathrm{ZnO}$ nanorods (reproduced with the permission from [54]).

crystal orientation in the deposited film. That is, the higher the oxygen contents in the carrier gas, the higher the density of (0001) orientations in the deposited film. Also, the SEM images of the $\mathrm{ZnO}$ nanorods grown on the two samples $\mathrm{ZnO}-\mathrm{B}$ and $\mathrm{ZnO}-\mathrm{C}$ indicate that annealing the seeding film enhances the quality of the single crystal $\mathrm{ZnO}$ nanorods in terms of their alignment, density, and size distribution. Also, Hung and Whang (2004) [70] fabricated $\mathrm{ZnO}$ seeding layer on silicon substrate through RF sputtering deposition and claimed growth of perfectly aligned nanorods on it. Henley et al. (2004) [71] used $\mathrm{ZnO}$ thin film, fabricated through Pulsed Laser Ablation (PLA) technique, as a seeding layer for the hydrothermal synthesis of $\mathrm{ZnO}$ nanorods, while Sun et al. (2006) [72] prepared a $\mathrm{ZnO}$ seeding film through Pulsed Laser Deposition (PLD) method.

Because of their simplicity and low cost, the liquidphase methods are extensively used for the deposition of seeding film on solid substrates. Baruah et al. (2008) [73], while growing $\mathrm{ZnO}$ nanorods on a nonwoven polyethylene fibers, followed the dip coating route for the deposition of seeding film. In this method, the ultra-clean substrate was first treated with $1 \%$ dodecane thiol solution in ethanol and dried at $100^{\circ} \mathrm{C}$. The thiol layer ensures better attachment of the seeding crystallites to the substrate [74]. The substrate was then dipped into the colloid of presynthesized $\mathrm{ZnO}$ nanoparticles for some time and then dried. This was repeated several times and a uniform layer of $\mathrm{ZnO}$ nanoparticles was formed at the substrate surface. The coated film was then subjected to annealing at about $350^{\circ} \mathrm{C}$. Hung and Whang (2003) [75] prepared $\mathrm{ZnO}$ nanocolloid by dissolving zinc acetate dihydrate and cetyltrimethylammonium hydroxide $(\mathrm{CTAOH})$ in ethanol with vigorous stirring at $60^{\circ} \mathrm{C}$ for $1 \mathrm{~h}$ and then cooled at room temperature. The colloid was used to form seeding film through dip coating. Zhao et al. (2006) [76] synthesized $\mathrm{ZnO}$ seeding film through dip coating for which the precursor was prepared by dissolving $\mathrm{Zn}\left(\mathrm{CH}_{3} \mathrm{COO}\right)_{2} \cdot 2 \mathrm{H}_{2} \mathrm{O}(0.75 \mathrm{~mol} / \mathrm{L})$ in a 2 -methoxyethanolmonoethanolamine (MEA) solution $(0.75 \mathrm{~mol} / \mathrm{L})$ at room temperature. The resultant solution was homogenized by stirring at $60^{\circ} \mathrm{C}$ for $30 \mathrm{~min}$. Subsequently, a clean glass substrate was dipped into the solution and withdrawn at various speeds. Thickness and texture of the film were reported to vary with dipping time, heating temperature, withdrawal speed, and cooling style. Ueno et al. (2010) [77] have seeded silicon substrate through spin coating (4000 rpm, 1 min) using precursor prepared by dissolving zinc acetate dihydrate and sodium dodecyl sulfate (SDS) in DI-water. The molar ratios in the precursor were $2 \mathrm{ZnAc}_{2}$ : $0.07 \mathrm{SDS}: 300 \mathrm{H}_{2} \mathrm{O}$. Guo et al. (2005) [78] reported that they have synthesized $\mathrm{ZnO}$ film on ITO substrates which were seeded through spin coating using colloid of presynthesized $\mathrm{ZnO}$ nanoparticles. Chen et al. (2009) [79] used ultrasonic spray pyrolysis (USP) method to fabricate the $\mathrm{ZnO}$ seeding film for the subsequent synthesis of $\mathrm{ZnO}$ nanorod arrays on ITO substrates, while Breedon et al. (2010) [80] used simple spray pyrolysis method to deposit the $\mathrm{ZnO}$ seed film on glass substrates. The precursor solution was prepared by dissolving zinc acetate dihydrate in DI-water and isopropyl alcohol mixed in ratio of $1: 3$ by volume. To increase the solubility of zinc acetate in the mixture solvent $0.4 \mathrm{~mL}$ of acetic acid was also added into the solution. The substrates were put on hot plate at temperature $450^{\circ} \mathrm{C}$, rotating at $25 \mathrm{rpm}$. The solution was sprayed on to the rotating hot substrates using $\mathrm{N}_{2}$ gas at pressure $2 \mathrm{~atm}$ from a distance of about $40 \mathrm{~cm}$. In a report by Baruah and Dutta (2009) [67], the authors have proposed a simple and efficient hydrothermal method for the deposition of seeding layer on glass substrates. In this method thin films of $\mathrm{ZnO}$ nanocrystallites were prepared by dip coating using $1 \mathrm{mM}$ zinc acetate solution in ethanol. Substrates were repeatedly heated at 100 and $120^{\circ} \mathrm{C}$ dipped into the precursor solutions and then annealed at different temperatures (100, 150, 200, 250,350 , and $450^{\circ} \mathrm{C}$ ) for 1 and $5 \mathrm{~h}$ wherein $\mathrm{ZnO}$ nanocrystallites were reported to form through in situ oxidation on hot substrates in open air. Working temperature of $120^{\circ} \mathrm{C}$ and annealing of the deposited film at $350^{\circ} \mathrm{C}$ were found as the optimum temperatures for the subsequent growth of well aligned $\mathrm{ZnO}$ nanorods, oriented along normal to the substrate. The method has been found to be more convenient and efficient than the one which involves dip coating of substrate with presynthesized $\mathrm{ZnO}$ nanoparticles. Since the presynthesized $\mathrm{ZnO}$ nanoparticles are aggregates of small units, therefore, a single particle can have several (001) facets oriented in random directions. Such seeds allow growth of as many $\mathrm{ZnO}$ nanorods to present flower-like morphologies as shown in Figure 9. In the in situ crystallization, the individual crystals are very small and distributed uniformly over the surface and, therefore, each seed allows a single rod to grow from it. This could be observed in Figure 10.

Mahmood and Dutta (2011) proposed spray pyrolysis as a cheap, easy, and fast route for the deposition of $\mathrm{ZnO}$ seeding film on glass substrates [81]. The technique involves spraying aqueous solution of zinc acetate on glass at nearly $400^{\circ} \mathrm{C}$. Utilizing oxygen from ambient air, zinc turns into zinc oxide and the high temperature of the substrate transforms it into $\mathrm{ZnO}$ nanocrystal strongly attached to the substrate. The assynthesized seeding layer has been found to be efficient in the subsequent growth of highly dense well aligned nanorod array. 


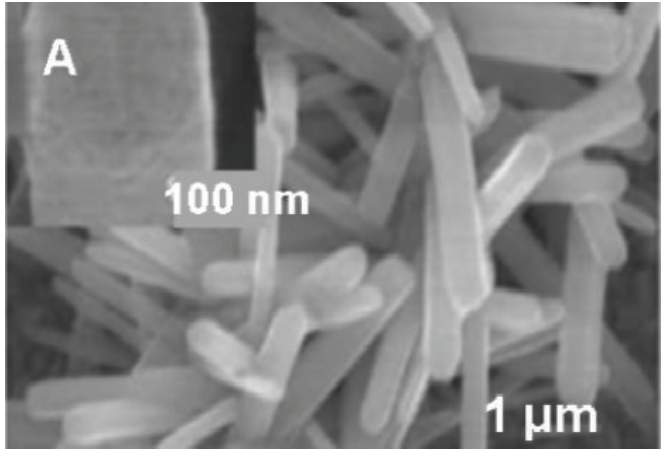

(a)

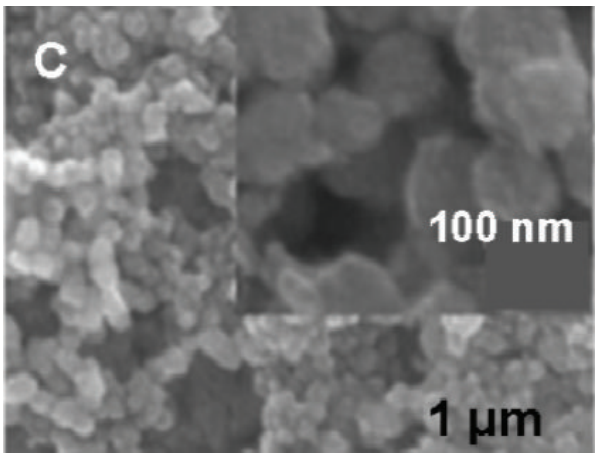

(c)

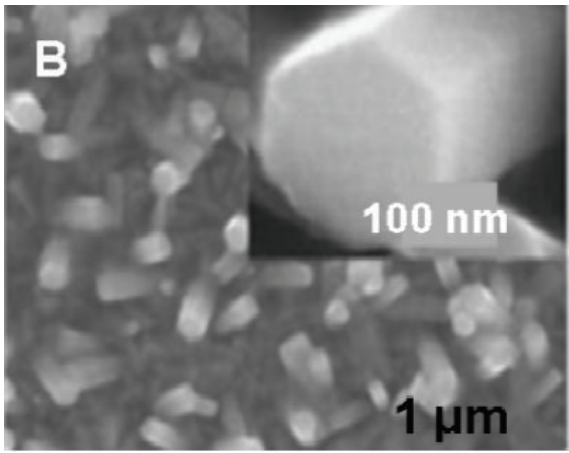

(b)

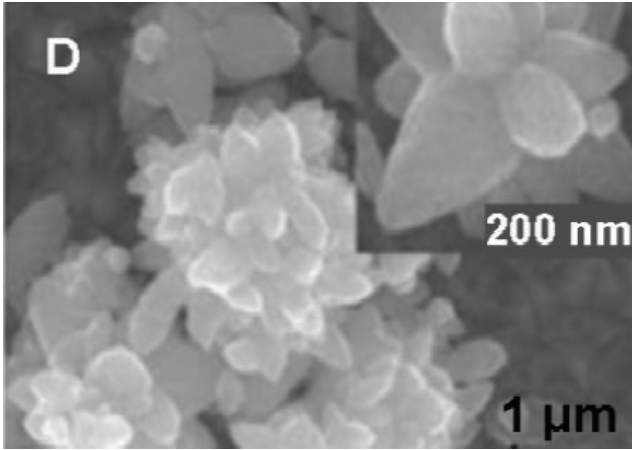

(d)

FIGURE 7: FESEM images showing the nanostructures obtained when growth was carried out at basic pH using $10 \mathrm{mM}$ reaction bath and growth duration of 5 hours (a) $\mathrm{pH}$ of 7.3, (b) $\mathrm{pH}$ of 8, (c) $\mathrm{pH}$ of 10, and (d) $\mathrm{pH}$ of 12 (reproduced with the permission from [54]).
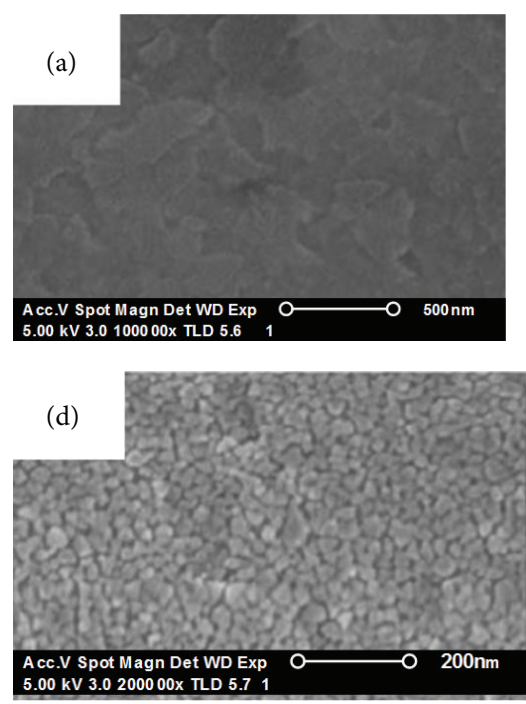
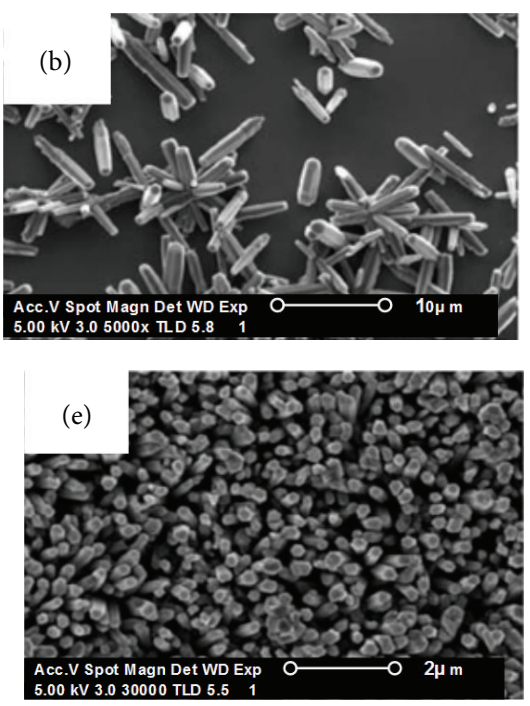
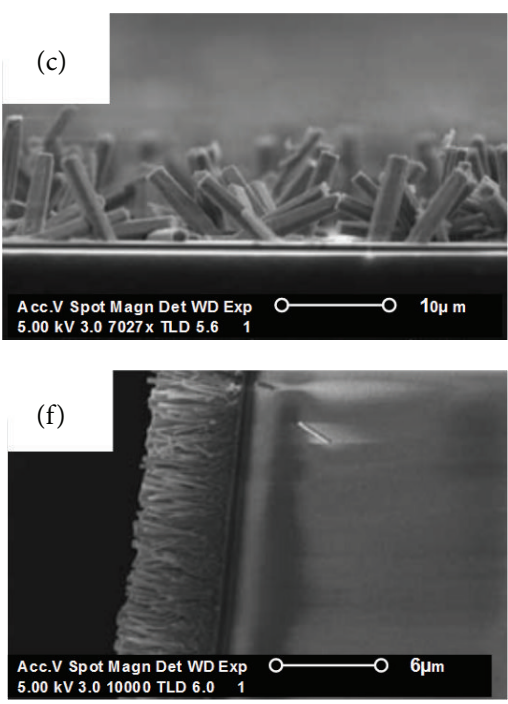

FIGURE 8: SEM images of ZnO nanorods and corresponding substrates. (a) Unmodified ITO substrate, (b) top view, (c) side view of ZnO nanorods grown on unmodified substrate, (d) PPT-substrate, (e) top view, and (f) side view of ZnO nanorods grown on PPT-substrate. Growth time: $2 \mathrm{~h}$ (reproduced with the permission from [47]).

TABLE 1: Detailed preparing parameters to grow different $\mathrm{ZnO}$ seed layers on Si substrates [69].

\begin{tabular}{lccccc}
\hline $\mathrm{ZnO}$ thin film & Temperature $\left({ }^{\circ} \mathrm{C}\right)$ & $\mathrm{Ar}: \mathrm{O}_{2}$ & Working pressure $(\mathrm{Pa})$ & Power $(\mathrm{W})$ & Annealing $\left({ }^{\circ} \mathrm{C}\right)$ \\
\hline $\mathrm{ZnO}-\mathrm{A}$ & 200 & $20: 3$ & $3 \times 10^{-5}$ & 100 & No \\
$\mathrm{ZnO}-\mathrm{B}$ & 200 & $20: 7$ & $3 \times 10^{-5}$ & 100 & No \\
$\mathrm{ZnO}-\mathrm{C}$ & 200 & $20: 7$ & $3 \times 10^{-5}$ & 100 & 400 \\
\hline
\end{tabular}




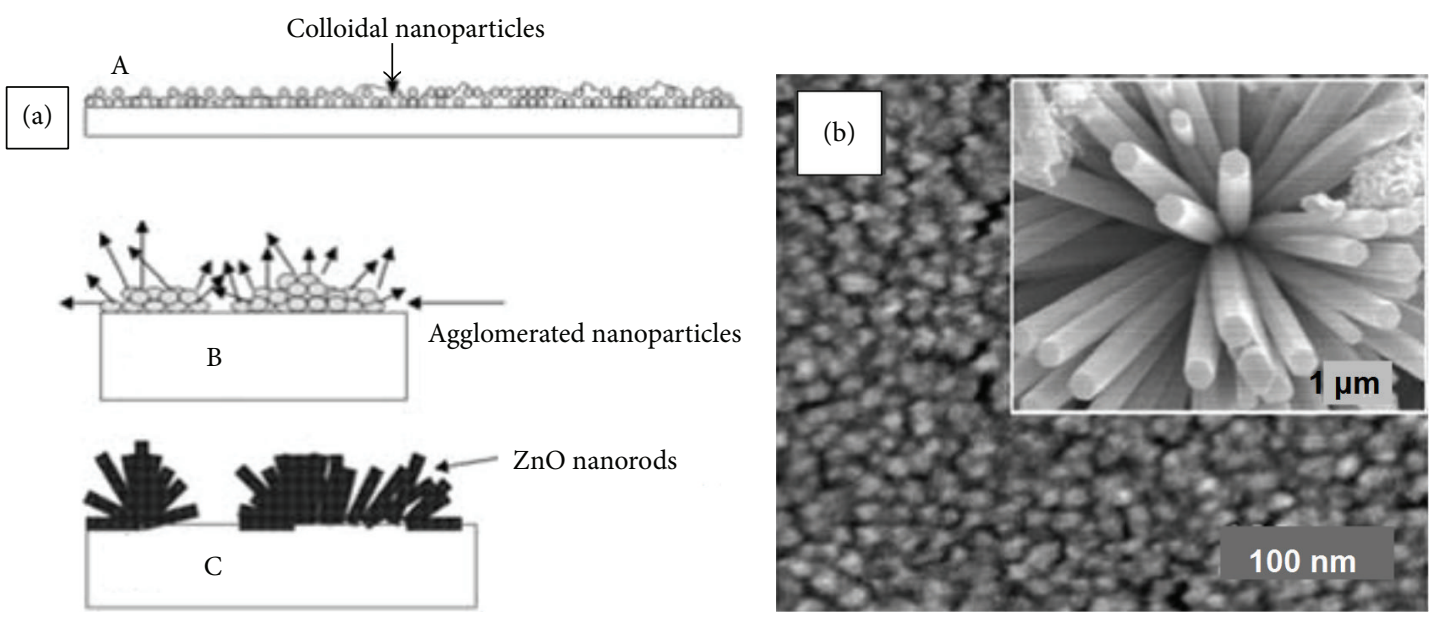

Figure 9: (a) Schematic diagram showing the possible agglomeration of $\mathrm{ZnO}$ nanoparticles upon evaporation of the solvent (A), thin layer of colloidal nanoparticles (B), and agglomerated clumps of $\mathrm{ZnO}$ nanoparticles with various orientations of the $c$-axes of the nanocrystallites (C). (b) Scanning electron microscope (SEM) image of $\mathrm{ZnO}$ particle seed layer using colloidal $\mathrm{ZnO}$ nanoparticles. Inset: $\mathrm{ZnO}$ nanorods grown using a $10 \mathrm{mM}$ growth solution for $15 \mathrm{~h}$ (reproduced with the permission from [60]).
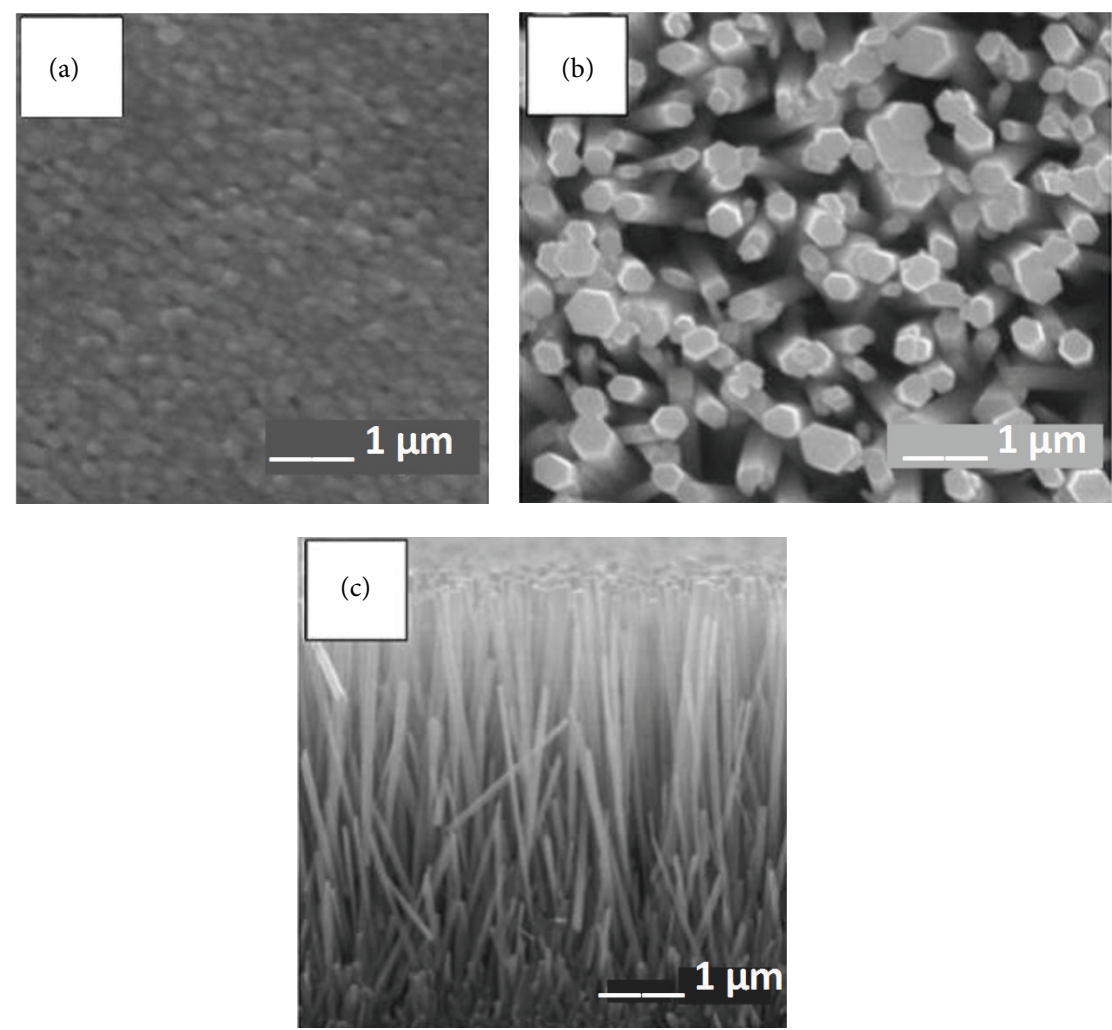

Figure 10: (a) $\mathrm{ZnO}$ seeds on glass substrate prepared from zinc acetate with a preheating temperature of $120^{\circ} \mathrm{C}$ and postannealing at $350^{\circ} \mathrm{C}$ for $5 \mathrm{~h}$. (b) Scanning electron microscopy (SEM) image of $\mathrm{ZnO}$ nanorods grown on substrate (a) and (c) cross-sectional view of the vertical nanorods (reproduced with the permission from [60]).

\section{Conclusion}

The low temperature hydrothermal method is an efficient, economical, and environmental friendly way of synthesizing $\mathrm{ZnO}$ nanocrystals. Precursor concentration, growth time, growth temperature, $\mathrm{pH}$ of the precursor solution, and availability of nucleation sites in the form of presynthesized polycrystalline layer of $\mathrm{ZnO}$ are the parameters which have profound influence over the growth rate, morphology, and orientation of the one-dimensional nanocrystals of zinc oxide. It has been concluded that proper adjustment of these parameters can help in synthesis of zinc oxide nanocrystals 
with the required size, density, orientation, and morphology for certain applications.

\section{Competing Interests}

The authors declare that they have no competing interests.

\section{Acknowledgments}

The authors would like to acknowledge every help and support provided by the University of Engineering and Technology Peshawar, Pakistan, in their ongoing research.

\section{References}

[1] C. F. Klingshirn, "ZnO: material, physics and applications," ChemPhysChem, vol. 8, no. 6, pp. 782-803, 2007.

[2] S. A. Kumar and S.-M. Chen, "Nanostructured zinc oxide particles in chemically modified electrodes for biosensor applications," Analytical Letters, vol. 41, no. 2, pp. 141-158, 2008.

[3] A. C. Mofor, A. El-Shaer, A. Bakin et al., "Magnetic property investigations on Mn-doped $\mathrm{ZnO}$ Layers on sapphire," Applied Physics Letters, vol. 87, no. 6, Article ID 062501, pp. 1-3, 2005.

[4] L. C. Tien, P. W. Sadik, D. P. Norton et al., "Hydrogen sensing at room temperature with $\mathrm{Pt}$-coated $\mathrm{ZnO}$ thin films and nanorods," Applied Physics Letters, vol. 87, no. 22, Article ID 222106, 3 pages, 2005.

[5] H. T. Wang, B. S. Kang, F. Ren et al., "Hydrogen-selective sensing at room temperature with $\mathrm{ZnO}$ nanorods," Applied Physics Letters, vol. 86, Article ID 243503, 2005.

[6] Z. L. Wang, “Ten years' venturing in $\mathrm{ZnO}$ nanostructures: from discovery to scientific understanding and to technology applications," Chinese Science Bulletin, vol. 54, article 4021, 14 pages, 2009.

[7] L. Wu, Y. Wu, and W. Lü, "Preparation of ZnO Nanorods and optical characterizations," Physica E: Low-Dimensional Systems and Nanostructures, vol. 28, no. 1, pp. 76-82, 2005.

[8] P.-Y. Kuang, J.-R. Ran, Z.-Q. Liu et al., "Enhanced photoelectrocatalytic activity of BiOI nanoplate-zinc oxide nanorod $\mathrm{p}-\mathrm{n}$ heterojunction," Chemistry-A European Journal, vol. 21, no. 43, pp. 15360-15368, 2015.

[9] P.-Y. Kuang, Y.-Z. Su, G.-F. Chen et al., " $\mathrm{g}-\mathrm{C}_{3} \mathrm{~N}_{4}$ decorated $\mathrm{ZnO}$ nanorod arrays for enhanced photoelectrocatalytic performance," Applied Surface Science, vol. 358, pp. 296-303, 2015.

[10] P.-Y. Kuang, Y.-Z. Su, K. Xiao et al., "Double-shelled CdS-and $\mathrm{CdSe}$-cosensitized $\mathrm{ZnO}$ porous nanotube arrays for superior photoelectrocatalytic applications," ACS Applied Materials \& Interfaces, vol. 7, no. 30, pp. 16387-16394, 2015.

[11] T.-Y. Ma, Z.-Y. Yuan, and J.-L. Cao, "Hydrangea-like meso-/ macroporous $\mathrm{ZnO}-\mathrm{CeO}_{2}$ binary oxide materials: synthesis, photocatalysis and CO oxidation," European Journal of Inorganic Chemistry, vol. 2010, no. 5, pp. 716-724, 2010.

[12] Y.-P. Zhu, M. Li, Y.-L. Liu, T.-Z. Ren, and Z.-Y. Yuan, “Carbondoped $\mathrm{ZnO}$ hybridized homogeneously with graphitic carbon nitride nanocomposites for photocatalysis," The Journal of Physical Chemistry C, vol. 118, no. 20, pp. 10963-10971, 2014.

[13] S. Baruah and J. Dutta, "Hydrothermal growth of $\mathrm{ZnO}$ nanostructures," Science and Technology of Advanced Materials, vol. 10, no. 1, Article ID 013001, 2009.
[14] Y. B. Li, Y. Bando, and D. Golberg, " $\mathrm{ZnO}$ nanoneedles with tip surface perturbations: excellent field emitters," Applied Physics Letters, vol. 84, no. 18, pp. 3603-3605, 2004.

[15] J. Wang, J. Cao, B. Fang, P. Lu, S. Deng, and H. Wang, "Synthesis and characterization of multipod, flower-like, and shuttle-like $\mathrm{ZnO}$ frameworks in ionic liquids," Materials Letters, vol. 59, no. 11, pp. 1405-1408, 2005.

[16] Z. L. Wang, "Nanostructures of zinc oxide," Materials Today, vol. 7, no. 6, pp. 26-33, 2004.

[17] N. Li, J.-Y. Wang, Z.-Q. Liu et al., "One-dimensional $\mathrm{ZnO} /$ $\mathrm{Mn}_{3} \mathrm{O}_{4}$ core/shell nanorod and nanotube arrays with high supercapacitive performance for electrochemical energy storage," RSC Advances, vol. 4, no. 33, pp. 17274-17281, 2014.

[18] Z.-Q. Liu, X.-H. Xie, Q.-Z. Xu et al., "Electrochemical synthesis of $\mathrm{ZnO} / \mathrm{CdTe}$ core-shell nanotube arrays for enhanced photoelectrochemical properties," Electrochimica Acta, vol. 98, pp. 268-273, 2013.

[19] Z. L. Wang, "Zinc oxide nanostructures: growth, properties and applications," Journal of Physics Condensed Matter, vol. 16, no. 25, pp. R829-R858, 2004.

[20] O. Dulub, L. A. Boatner, and U. Diebold, "STM study of the geometric and electronic structure of $\mathrm{ZnO}\left(\begin{array}{llll}0 & 0 & 0 & 1\end{array}\right)-\mathrm{Zn},\left(\begin{array}{llll}0 & 0 & 0\end{array}\right.$

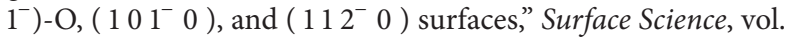
519, no. 3, pp. 201-217, 2002.

[21] B. Meyer and D. Marx, "Density-functional study of the structure and stability of $\mathrm{ZnO}$ surfaces," Physical Review B: Condensed Matter, vol. 67, no. 3, pp. 354031-354011, 2003.

[22] P. W. Tasker, “The stability of ionic crystal surfaces," Journal of Physics C: Solid State Physics, vol. 12, no. 22, pp. 4977-4984, 1979.

[23] O. Dulub, U. Diebold, and G. Kresse, "Novel stabilization mechanism on polar surfaces: $\mathrm{ZnO}(0001)-\mathrm{Zn}$," Physical Review Letters, vol. 90, no. 1, Article ID 016102, 4 pages, 2003.

[24] A. Wander, F. Schedin, P. Steadman et al., "Stability of polar oxide surfaces," Physical Review Letters, vol. 86, no. 17, pp. 38113814, 2001.

[25] V. Staemmler, K. Fink, B. Meyer et al., "Stabilization of polar $\mathrm{ZnO}$ surfaces: validating microscopic models by using $\mathrm{CO}$ as a probe molecule," Physical Review Letters, vol. 90, no. 10, Article ID 106102, 2003.

[26] M. Bowker, H. Houghton, K. C. Waugh, T. Giddings, and M. Green, "Crystal plane dependence of adsorption and reaction on zinc oxide," Journal of Catalysis, vol. 84, no. 1, pp. 252-255, 1983.

[27] L. Spanhel, "Colloidal $\mathrm{ZnO}$ nanostructures and functional coatings: a survey," Journal of Sol-Gel Science and Technology, vol. 39, no. 1, pp. 7-24, 2006.

[28] M. Kohls, M. Bonanni, L. Spanhel, D. Su, and M. Giersig, "Green $\mathrm{Er}^{\mathrm{III}}$ luminescence in fractal $\mathrm{ZnO}$ nanolattices," Applied Physics Letters, vol. 81, no. 20, pp. 3858-3860, 2002.

[29] X. Ma, H. Zhang, Y. Ji, J. Xu, and D. Yang, "Sequential occurrence of $\mathrm{ZnO}$ nanopaticles, nanorods, and nanotips during hydrothermal process in a dilute aqueous solution," Materials Letters, vol. 59, no. 27, pp. 3393-3397, 2005.

[30] H. Xu, H. Wang, Y. Zhang, S. Wang, M. Zhu, and H. Yan, "Asymmetric twinning crystals of zinc oxide formed in a hydrothermal process," Crystal Research and Technology, vol. 38, no. 6, pp. 429-432, 2003.

[31] S. Shingubara, "Fabrication of nanomaterials using porous alumina templates," Journal of Nanoparticle Research, vol. 5, no. 1-2, pp. 17-30, 2003. 
[32] J.-H. Lee, I.-C. Leu, Y.-W. Chung, and M.-H. Hon, "Fabrication of ordered $\mathrm{ZnO}$ hierarchical structures controlled via surface charge in the electrophoretic deposition process," Nanotechnology, vol. 17, no. 17, pp. 4445-4450, 2006.

[33] M. Krunks and E. Mellikov, "Zinc oxide thin films by the spray pyrolysis method," Thin Solid Films, vol. 270, no. 1-2, pp. 33-36, 1995.

[34] R. Ayouchi, F. Martin, D. Leinen, and J. R. Ramos-Barrado, "Growth of pure $\mathrm{ZnO}$ thin films prepared by chemical spray pyrolysis on silicon," Journal of Crystal Growth, vol. 247, no. 3-4, pp. 497-504, 2003.

[35] S. H. Dalal, D. L. Baptista, K. B. K. Teo, R. G. Lacerda, D. A. Jefferson, and W. I. Milne, "Controllable growth of vertically aligned zinc oxide nanowires using vapour deposition," Nanotechnology, vol. 17, no. 19, pp. 4811-4818, 2006.

[36] Y. Satoh, S. Ohshio, and H. Saitoh, "Photoluminescence spectroscopy of highly oriented $\mathrm{Y}_{2} \mathrm{O}_{3}: \mathrm{Tb}$ crystalline whiskers," Science and Technology of Advanced Materials, vol. 6, no. 2, pp. 215-218, 2005.

[37] T. Yasuda and Y. Segawa, "Zinc oxide thin films synthesized by metal organic chemical reactions," Physica Status Solidi (B), vol. 241, no. 3, pp. 676-679, 2004.

[38] C. C. Tang, S. S. Fan, M. L. D. L. Chapelle, and P. Li, "Silica-assisted catalytic growth of oxide and nitride nanowires," Chemical Physics Letters, vol. 333, no. 1-2, pp. 12-15, 2001.

[39] Z. Wang and H. L. Li, "Highly ordered zinc oxide nanotubules synthesized within the anodic aluminum oxide template," Applied Physics A, vol. 74, no. 2, pp. 201-203, 2002.

[40] P. Zheng Wei, D. Zu Rong, and W. Zhong Lin, "Nanobelts of semiconducting oxides," Science, vol. 291, no. 5510, pp. 19471949, 2001.

[41] L. Miao, Y. Ieda, S. Tanemura et al., "Synthesis, microstructure and photoluminescence of well-aligned $\mathrm{ZnO}$ nanorods on $\mathrm{Si}$ substrate," Science and Technology of Advanced Materials, vol. 8, no. 6, pp. 443-447, 2007.

[42] Z. W. Li and W. Gao, "Growth of zinc oxide thin films and nanostructures by wet oxidation," Thin Solid Films, vol. 515, no. 7-8, pp. 3323-3329, 2007.

[43] A. Lagashetty, V. Havanoor, S. Basavaraja, S. D. Balaji, and A. Venkataraman, "Microwave-assisted route for synthesis of nanosized metal oxides," Science and Technology of Advanced Materials, vol. 8, no. 6, pp. 484-493, 2007.

[44] M. A. Vergés, A. Mifsud, and C. J. Serna, "Formation of rod-like zinc oxide microcrystals in homogeneous solutions," Journal of the Chemical Society, Faraday Transactions, vol. 86, no. 6, pp. 959-963, 1990.

[45] L. Vayssieres, K. Keis, S.-E. Lindquist, and A. Hagfeldt, "Purpose-built anisotropie metal oxide material: $3 \mathrm{D}$ highly oriented microrod array of ZnO," The Journal of Physical Chemistry B, vol. 105, no. 17, pp. 3350-3352, 2001.

[46] L. Schmidt-Mende and J. L. MacManus-Driscoll, " $\mathrm{ZnO}-$ nanostructures, defects, and devices," Materials Today, vol. 10, no. 5, pp. 40-48, 2007.

[47] M. Guo, P. Diao, and S. Cai, "Hydrothermal growth of wellaligned $\mathrm{ZnO}$ nanorod arrays: dependence of morphology and alignment ordering upon preparing conditions," Journal of Solid State Chemistry, vol. 178, no. 6, pp. 1864-1873, 2005.

[48] H. Q. Le, S. J. Chua, Y. W. Koh, K. P. Loh, and E. A. Fitzgerald, "Systematic studies of the epitaxial growth of single-crystal $\mathrm{ZnO}$ nanorods on GaN using hydrothermal synthesis," Journal of Crystal Growth, vol. 293, no. 1, pp. 36-42, 2006.
[49] S.-F. Wang, T.-Y. Tseng, Y.-R. Wang, C.-Y. Wang, H.-C. Lu, and W.-L. Shih, "Effects of preparation conditions on the growth of $\mathrm{ZnO}$ nanorod arrays using aqueous solution method," International Journal of Applied Ceramic Technology, vol. 5, no. 5, pp. 419-429, 2008.

[50] K. M. Lee, K. H. Park, K. H. Koh, and S. Lee, "Synthesis of high quality $\mathrm{ZnO}$ nanorods by low temperature wet chemical process," in Proceedings of the 2 nd IEEE International Conference on Nano/Micro Engineered and Molecular Systems (IEEE NEMS '07), pp. 775-778, Bangkok, Thailand, January 2007.

[51] S. Xu, C. Lao, B. Weintraub, and Z. L. Wang, "Density-controlled growth of aligned $\mathrm{ZnO}$ nanowire arrays by seedles chemical approach on smooth surfaces," Journal of Materials Research, vol. 23, no. 8, pp. 2072-2077, 2008.

[52] M. A. Mahmood, T. Bora, and J. Dutta, "Studies on hydrothermally synthesised zinc oxide nanorod arrays for their enhanced visible light photocatalysis," International Journal of Environmental Technology and Management, vol. 16, no. 1-2, pp. 146-159, 2013.

[53] L. Z. Pei, H. S. Zhao, W. Tan et al., "Hydrothermal oxidization preparation of $\mathrm{ZnO}$ nanorods on zinc substrate," Physica E: Low-Dimensional Systems and Nanostructures, vol. 42, no. 5, pp. 1333-1337, 2010.

[54] S. Baruah and J. Dutta, "pH-dependent growth of zinc oxide nanorods," Journal of Crystal Growth, vol. 311, no. 8, pp. 25492554, 2009.

[55] M. N. R. Ashfold, R. P. Doherty, N. G. Ndifor-Angwafor, D. J. Riley, and Y. Sun, "The kinetics of the hydrothermal growth of $\mathrm{ZnO}$ nanostructures," Thin Solid Films, vol. 515, no. 24, pp. 8679-8683, 2007.

[56] A. Sugunan, H. C. Warad, M. Boman, and J. Dutta, "Zinc oxide nanowires in chemical bath on seeded substrates: role of hexamine," Journal of Sol-Gel Science and Technology, vol. 39, no. 1, pp. 49-56, 2006.

[57] Z. Zhou, Y. Zhao, and Z. Cai, "Low-temperature growth of $\mathrm{ZnO}$ nanorods on PET fabrics with two-step hydrothermal method," Applied Surface Science, vol. 256, no. 14, pp. 4724-4728, 2010.

[58] L. Tang, X.-B. Bao, H. Zhou, and A.-H. Yuan, "Synthesis and characterization of $\mathrm{ZnO}$ nanorods by a simple single-source hydrothermal method," Physica E: Low-Dimensional Systems and Nanostructures, vol. 40, no. 4, pp. 924-928, 2008.

[59] M. Guo, P. Diao, X. Wang, and S. Cai, "The effect of hydrothermal growth temperature on preparation and photoelectrochemical performance of $\mathrm{ZnO}$ nanorod array films," Journal of Solid State Chemistry, vol. 178, no. 10, pp. 3210-3215, 2005.

[60] K. Hou, C. Li, W. Lei et al., "Influence of synthesis temperature on $\mathrm{ZnO}$ nanostructure morphologies and field emission properties," Physica E: Low-Dimensional Systems and Nanostructures, vol. 41, no. 3, pp. 470-473, 2009.

[61] F. Li, L. Hu, Z. Li, and X. Huang, "Influence of temperature on the morphology and luminescence of $\mathrm{ZnO}$ micro and nanostructures prepared by CTAB-assisted hydrothermal method," Journal of Alloys and Compounds, vol. 465, no. 1-2, pp. L14-L19, 2008.

[62] R. Wahab, S. G. Ansari, H.-K. Seo, Y. S. Kim, E.-K. Suh, and H.-S. Shin, "Low temperature synthesis and characterization of rosette-like nanostructures of $\mathrm{ZnO}$ using solution process," Solid State Sciences, vol. 11, no. 2, pp. 439-443, 2009.

[63] D. Sridevi and K. V. Rajendran, "Preparation of ZnO nanoparticles and nanorods by using CTAB assisted hydrothermal method," International Journal of Nanotechnology and Applications, vol. 3, no. 2, pp. 43-48, 2009. 
[64] J. Song, S. Baek, J. Lee, and S. Lim, "Role of OH- in the low temperature hydrothermal synthesis of $\mathrm{ZnO}$ nanorods," Journal of Chemical Technology and Biotechnology, vol. 83, no. 3, pp. 345-350, 2008.

[65] O. Akhavan, M. Mehrabian, K. Mirabbaszadeh, and R. Azimi$\mathrm{rad}$, "Hydrothermal synthesis of $\mathrm{ZnO}$ nanorod arrays for photocatalytic inactivation of bacteria," Journal of Physics D: Applied Physics, vol. 42, no. 22, Article ID 225305, 2009.

[66] C. Li, Z. Jin, H. Chu, and Y. Li, "Seed-mediated growth of $\mathrm{ZnO}$ nanorods on multiwalled carbon nanotubes," Journal of Nanoscience and Nanotechnology, vol. 8, no. 9, pp. 4441-4446, 2008.

[67] S. Baruah and J. Dutta, "Effect of seeded substrates on hydrothermally grown $\mathrm{ZnO}$ nanorods," Journal of Sol-Gel Science and Technology, vol. 50, no. 3, pp. 456-464, 2009.

[68] S.-F. Wang, T.-Y. Tseng, Y.-R. Wang, C.-Y. Wang, and H.-C. Lu, "Effect of $\mathrm{ZnO}$ seed layers on the solution chemical growth of $\mathrm{ZnO}$ nanorod arrays," Ceramics International, vol. 35, no. 3, pp. 1255-1260, 2009.

[69] Y. Tao, M. Fu, A. Zhao, D. He, and Y. Wang, "The effect of seed layer on morphology of $\mathrm{ZnO}$ nanorod arrays grown by hydrothermal method," Journal of Alloys and Compounds, vol. 489, no. 1, pp. 99-102, 2010.

[70] C.-H. Hung and W.-T. Whang, "Low-temperature solution approach toward highly aligned $\mathrm{ZnO}$ nanotip arrays," Journal of Crystal Growth, vol. 268, no. 1-2, pp. 242-248, 2004.

[71] S. J. Henley, M. N. R. Ashfold, D. P. Nicholls, P. Wheatley, and $\mathrm{D}$. Cherns, "Controlling the size and alignment of $\mathrm{ZnO}$ microrods using $\mathrm{ZnO}$ thin film templates deposited by pulsed laser ablation," Applied Physics A, vol. 79, no. 4-6, pp. 1169-1173, 2004.

[72] Y. Sun, N. George Ndifor-Angwafor, D. Jason Riley, and M. N. R. Ashfold, "Synthesis and photoluminescence of ultra-thin $\mathrm{ZnO}$ nanowire/nanotube arrays formed by hydrothermal growth," Chemical Physics Letters, vol. 431, no. 4-6, pp. 352-357, 2006.

[73] S. Baruah, C. Thanachayanont, and J. Dutta, "Growth of $\mathrm{ZnO}$ nanowires on nonwoven polyethylene fibers," Science and Technology of Advanced Materials, vol. 9, no. 2, Article ID 025009, 2008.

[74] E. Maria Claesson and A. P. Philipse, "Thiol-functionalized silica colloids, grains, and membranes for irreversible adsorption of metal(oxide) nanoparticles," Colloids and Surfaces A: Physicochemical and Engineering Aspects, vol. 297, no. 1-3, pp. 46-54, 2007.

[75] C.-H. Hung and W.-T. Whang, "A novel low-temperature growth and characterization of single crystal $\mathrm{ZnO}$ nanorods," Materials Chemistry and Physics, vol. 82, no. 3, pp. 705-710, 2003.

[76] J. Zhao, Z.-G. Jin, T. Li, and X.-X. Liu, "Nucleation and growth of $\mathrm{ZnO}$ nanorods on the $\mathrm{ZnO}$-coated seed surface by solution chemical method," Journal of the European Ceramic Society, vol. 26, no. 13, pp. 2769-2775, 2006.

[77] N. Ueno, T. Maruo, N. Nishiyama, Y. Egashira, and K. Ueyama, "Low-temperature synthesis of $\mathrm{ZnO}$ nanorods using a seed layer of zinc acetate/sodium dodecyle sulfate nanocomposite," Materials Letters, vol. 64, no. 4, pp. 513-515, 2010.

[78] M. Guo, P. Diao, and S. Cai, "Hydrothermal growth of perpendicularly oriented $\mathrm{ZnO}$ nanorod array film and its photoelectrochemical properties," Applied Surface Science, vol. 249, no. 1-4, pp. 71-75, 2005.

[79] J. Chen, W. Lei, and X. B. Zhang, "Field emission property improved by $\mathrm{ZnO}$ acicular nanostructure through chemical bath deposition," in Proceedings of the IEEE International Vacuum Electronics Conference (IVEC '09), pp. 195-198, Rome, Italy, April 2009.

[80] M. Breedon, M. B. Rahmani, S.-H. Keshmiri, W. Wlodarski, and K. Kalantar-zadeh, "Aqueous synthesis of interconnected $\mathrm{ZnO}$ nanowires using spray pyrolysis deposited seed layers," Materials Letters, vol. 64, no. 3, pp. 291-294, 2010.

[81] M. A. Mahmood and J. Dutta, "Spray pyrolized pre-coating layers for controlled growth of zinc oxide nanorods by hydrothermal process," Nanoscience \& Nanotechnology-Asia, vol. 1, no. 2, pp. 92-96, 2011. 

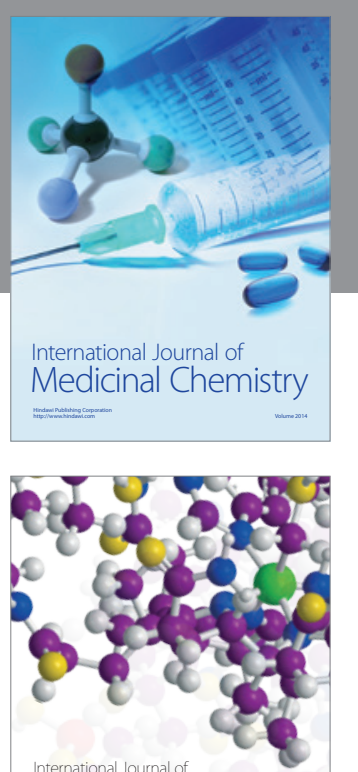

Carbohydrate Chemistry

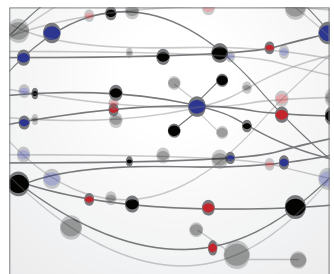

The Scientific World Journal
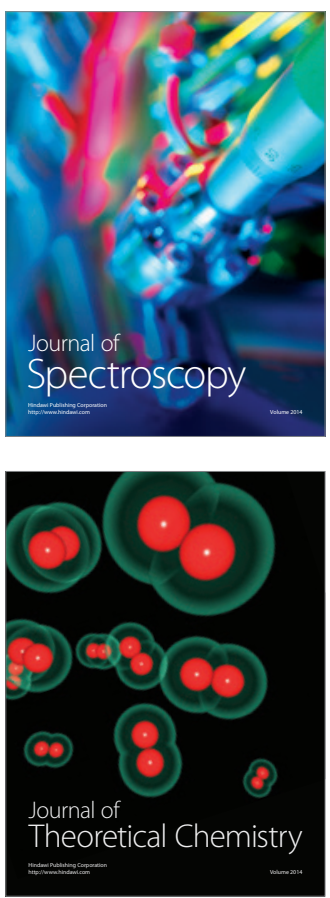
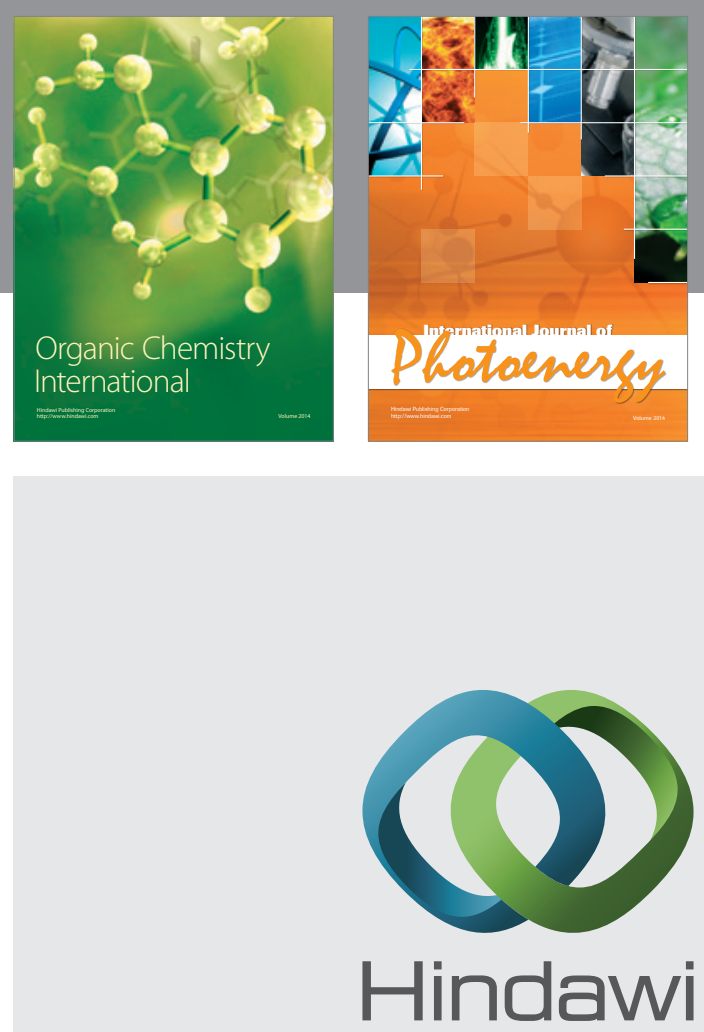

Submit your manuscripts at

http://www.hindawi.com

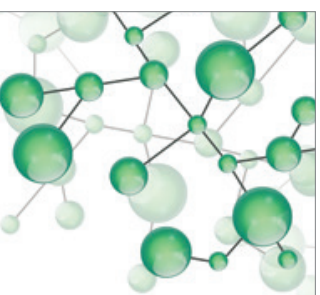

International Journal of

Inorganic Chemistry

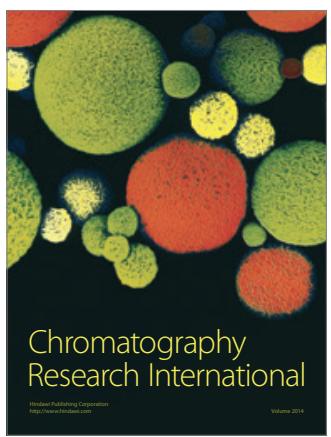

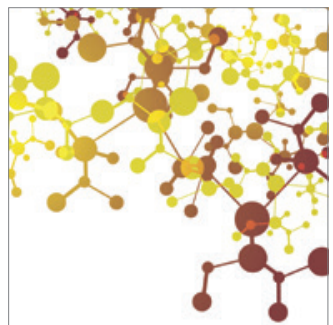

Applied Chemistry
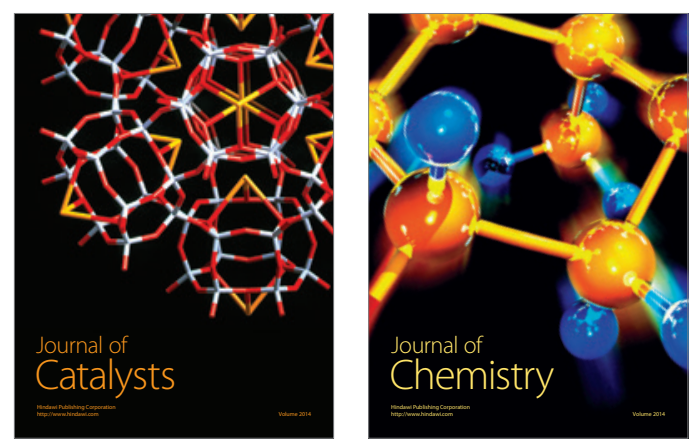
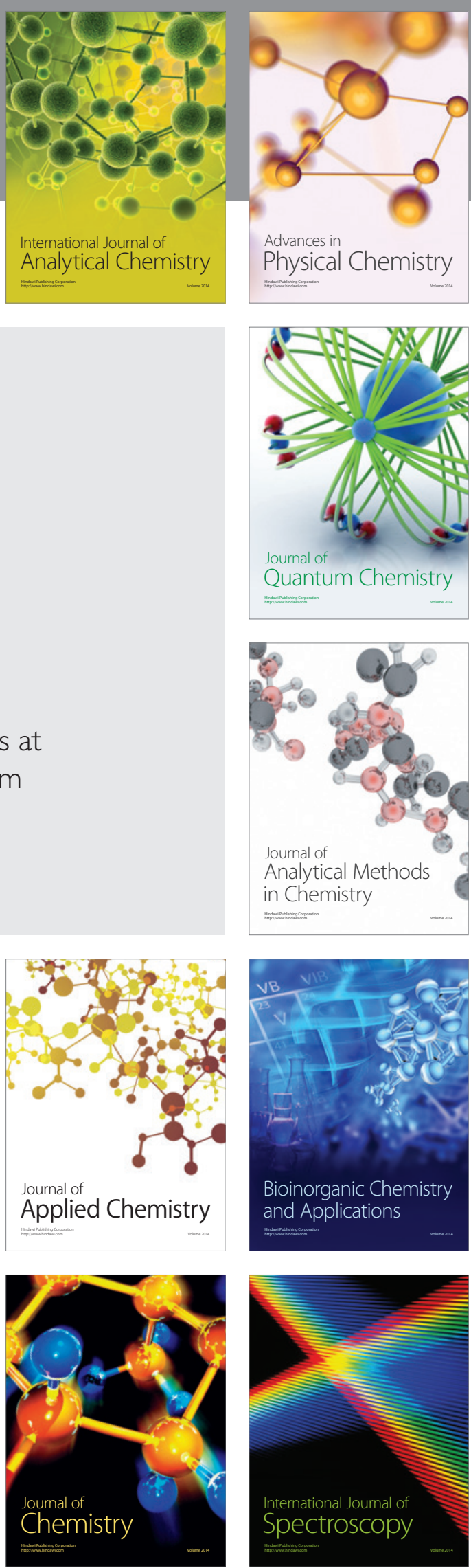